\title{
Managing the overlap of asthma and chronic obstructive pulmonary disease
}

\section{SUMMARY}

Approximately $20 \%$ of patients with obstructive lung disease have features of both asthma and chronic obstructive pulmonary disease.

These patients have a higher burden of disease and increased exacerbations compared to those with asthma or chronic obstructive pulmonary disease alone.

Management should address dominant clinical features in each individual patient, and comorbidities should be considered.

There are several interventions that are useful in the management of both asthma and chronic obstructive pulmonary disease.

As inhaled corticosteroids are key to the management of asthma, they are recommended in patients with overlapping chronic obstructive pulmonary disease.

\section{Introduction}

Asthma and chronic obstructive pulmonary disease (COPD) are both common inflammatory diseases of the airways. They are usually distinct disorders but approximately $20 \%$ of patients with obstructive lung disease will have features of both conditions. ${ }^{1,2}$ Asthma-COPD overlap is a term sometimes used to refer to this group of patients, but consensus on a precise definition is lacking. ${ }^{2}$ Contributing to the controversy around a definition is the heterogeneity of clinical manifestations within this group and the relative importance of each disorder in an individual. ${ }^{3}$

COPD is characterised by persistent respiratory symptoms and airflow limitation, due to a combination of small airways disease and parenchymal destruction (i.e. emphysema). It is usually caused by exposure to noxious gases and particles, most commonly tobacco smoke. ${ }^{4}$ Asthma is characterised by variable respiratory symptoms and airway narrowing from bronchoconstriction and airway inflammation.

Dual diagnoses of asthma and COPD have often been an exclusion criterion for clinical trials investigating the individual conditions. This has limited the availability of evidence to guide clinical management. A global survey on the diagnosis and management of asthmaCOPD overlap highlighted uncertainty among GPs and specialists on the clinical approach to this group of patients.

\section{Diagnosis}

The diagnosis of asthma-COPD overlap is based on symptoms and an assessment of lung function and airway inflammation.

\section{Symptoms of asthma and COPD}

Asthma commonly starts in childhood. The symptoms of breathlessness, chest tightness, cough and wheeze are variable from day to day but are worse in the night and early morning. Features of other allergic conditions such as rhinitis and eczema may be present and there may be a family history of asthma. Typical triggers of asthma may be identified, such as house dust, pollens and grasses.

Persistent dyspnoea that worsens with exercise and progresses over time is suggestive of COPD. Intermittent cough, with or without sputum production, and wheeze, may also be present. There may be a history of recurrent chest infections and flares (exacerbations) of respiratory symptoms. Onset is usually in midlife, and there is typically a history of cigarette smoking or exposure to other noxious agents associated with indoor or outdoor pollution.

The coexistence of asthma and chronic obstructive lung disease should be suspected in middle-aged or older patients with:

- a history of cigarette smoking

- a diagnosis of asthma before the age of 40 years

- clinical features of both diseases.

\section{Anne Knight}

Thoracic and general physician, Hunter New England Local Health District, Taree, NSW

Senior lecturer, University of Newcastle Department of Rural Health, NSW

\section{Keywords}

asthma, bronchodilators, COPD, corticosteroids, eosinophils, inhalers, obstructive lung disease

Aust Prescr 2020;43:7-11 https://doi.org/10.18773/ austprescr.2020.002 


\section{Spirometry}

The diagnosis of obstructive lung disease relies on spirometry (see Fig). Pre- and post-bronchodilator spirometry should be performed. A ratio of postbronchodilator forced expiratory volume in one second $\left(F E V_{1}\right)$ to forced vital capacity $\left(F E V_{1} / F V C\right)$ of less than 0.7 confirms persistent airflow limitation consistent with COPD. ${ }^{4}$

Reversibility can be defined as an $\mathrm{FEV}_{1}$ increase of over $12 \%$ and more than $200 \mathrm{~mL}$ following bronchodilator use. While some reversibility of airflow limitation with bronchodilators may be found in patients with COPD alone, an FEV increase of more than $400 \mathrm{~mL}$ suggests coexisting asthma. ${ }^{6}$ However, there is also a subgroup of patients with long-standing asthma who have fixed airflow obstruction in whom reversibility cannot be demonstrated. These patients often have a long history of asthma that is difficult to control and are usually under the care of specialists.

\section{Fig. Examples of typical spirometry tracings in asthma, COPD} and asthma-COPD overlap
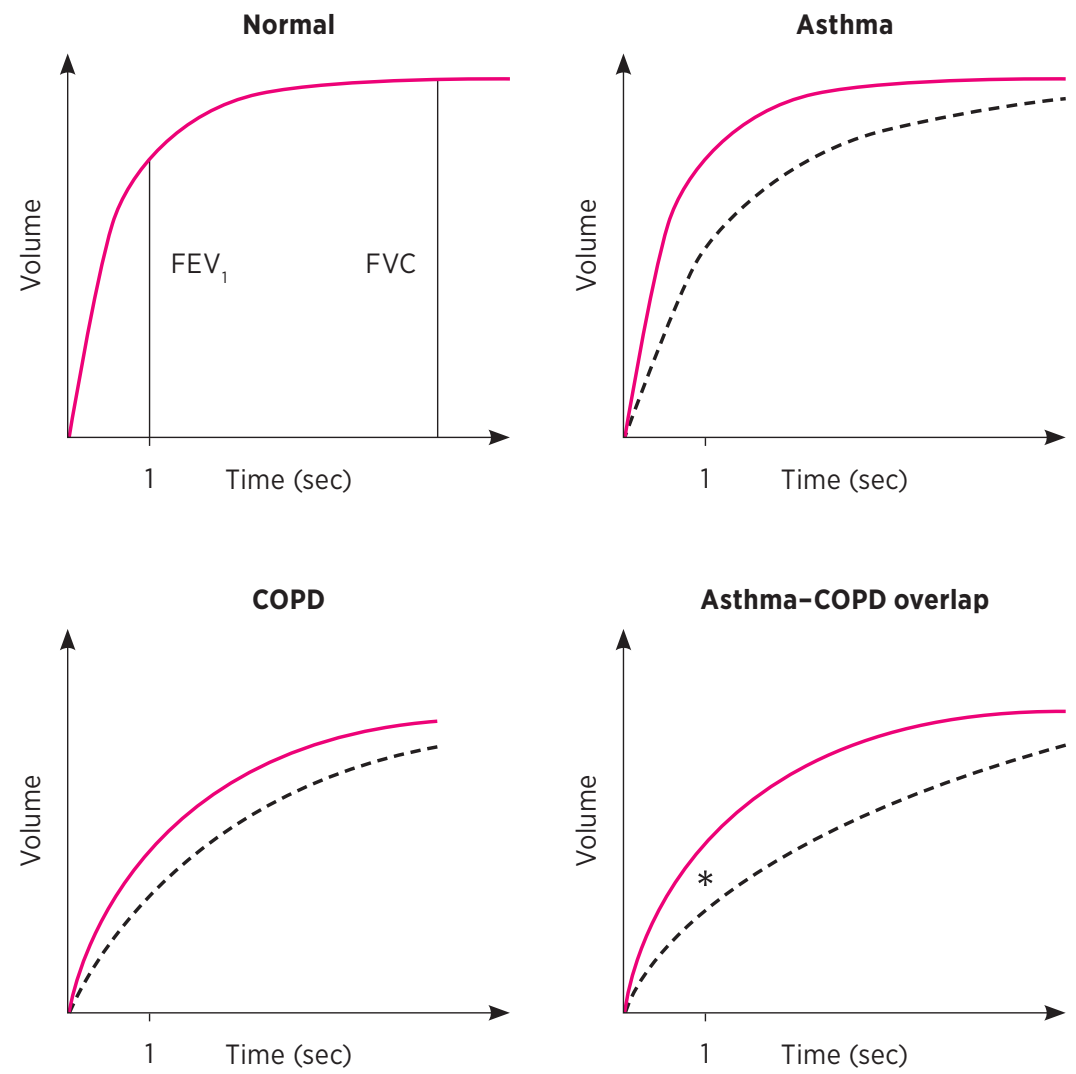

\footnotetext{
- - - pre-bronchodilator _ post-bronchodilator

* Difference between pre- and post-bronchodilator FEV ${ }_{1}$ more than $400 \mathrm{~mL}$.

FEV , forced expiratory volume in 1 second

FVC forced vital capacity

COPD chronic obstructive pulmonary disease
}

\section{Airway inflammation}

Asthma is characterised predominantly by eosinophilic and type 2 helper T lymphocyte-driven inflammation of the airways, whereas COPD typically involves neutrophilic inflammation. ${ }^{7}$ In recent years the heterogeneity of airway inflammation in asthma, COPD and asthma-COPD overlap has been recognised, with eosinophilic, neutrophilic, mixed or paucigranulocytic inflammation occurring in all of these conditions. ${ }^{1}$

Eosinophilic airway inflammation may predict a favourable response to inhaled corticosteroids. Blood eosinophils have been suggested as a biomarker to support clinical decisions regarding the use of inhaled corticosteroids in patients with COPD. Patients with eosinophil blood counts of more than 300 cells/microlitre $\left(0.3 \times 10^{9} / \mathrm{L}\right)$ are more likely to benefit.4,8

Systemic glucocorticoids will reduce the eosinophil count in blood, so the test should not be done while the patient is taking oral corticosteroids. Further prospective studies are required to elucidate the role of eosinophils in determining likelihood of response to inhaled corticosteroids in patients with asthmaCOPD overlap.

Other measures of airway inflammation such as exhaled nitric oxide fraction and sputum eosinophilia are not readily available outside specialist centres.

\section{Implications of overlapping asthma and COPD}

Patients with coexisting asthma and COPD have an increased illness burden' compared to those with asthma or COPD alone. They have more frequent and severe exacerbations ${ }^{9}$ and hospitalisations. This is despite having had fewer pack-years of smoking than those with COPD alone. ${ }^{9}$ Mortality may also be increased. ${ }^{1,10}$

Asthma may also be a risk factor for developing COPD. ${ }^{1,4,11}$ In severe asthma, structural changes such as airway remodelling can contribute to fixed airway obstruction and smaller airway size. Single nucleotide polymorphisms have been identified in biologically plausible genes associated with asthma-COPD overlap but their significance is unclear. $^{9}$

\section{Management}

Consideration of the dominant features or traits in an individual patient can provide a useful framework for approaching the management of overlapping disease. There are several interventions that are useful in both COPD and asthma (see Box), and it is important that these are incorporated into the management of these patients. 


\section{Box Interventions useful in both COPD and asthma}

Bronchodilators for symptom control

Inhaled corticosteroids for nearly all patients with asthma and selected patients with COPD

Systemic glucocorticoids for severe exacerbations Smoking cessation

Annual influenza vaccination

Correction of inhaler technique

Written action plan

Management of comorbidities

COPD chronic obstructive pulmonary disease

\section{Smoking cessation}

Tobacco smoking is the most important risk factor for COPD, and the rate of decline in lung function can be slowed by stopping smoking. In patients with asthma, smoking is associated with progression to severe asthma and reduced glucocorticoid sensitivity. ${ }^{12}$ It is therefore important to identify people with obstructive lung disease who continue to smoke and provide advice and support to help them stop. This involves both behavioural support and treatment of nicotine dependence, for example with nicotine replacement therapy, varenicline or bupropion. ${ }^{6}$

\section{Vaccination}

Annual influenza vaccination reduces exacerbations in patients with COPD, with only minor adverse effects. It is also recommended for patients with asthma. 13-15

Pneumococcal vaccination can be given at the same time as inactivated influenza vaccine. ${ }^{13}$ Polysaccharide pneumococcal vaccines provide protection against community-acquired pneumonia and exacerbations in patients with COPD. ${ }^{16}$ There are also benefits for patients with asthma as those with severe disease have an increased risk of invasive pneumococcal disease.

The Australian Immunisation Handbook provides up-to-date clinical advice on the appropriate vaccines to use and timing of revaccination. ${ }^{13}$

\section{Inhaler technique}

Inhaled therapies are the foundation of pharmacotherapy for asthma, COPD and asthma-COPD overlap. Poor technique is common and associated with a worse prognosis in asthma and COPD. ${ }^{17,18}$ There has been an increase in the number of different devices available in the past few years, which has increased the likelihood of handling errors. Currently available inhaler devices can be viewed in Lung Foundation Australia's Stepwise Management of Stable COPD brochure.
When inhaled therapies are started or changed, education by the prescriber should include instruction, visual demonstration and observation of patient technique. Metered-dose inhalers should be used with a valved spacer where possible. Technique should be reviewed and reinforced regularly. ${ }^{6}$ Resources to assist with inhaler technique include 'How-to videos' available from the National Asthma Council Australia. Community pharmacists, respiratory and primary care nurses, and physiotherapists can also assist with patient education.

\section{Bronchodilators}

Short-acting beta ${ }_{2}$ agonists (salbutamol or terbutaline) can be used for short-term symptom relief in asthma, COPD and asthma-COPD overlap. Recent guidelines recommend against treating asthma in adults with short-acting bronchodilators alone..$^{19}$ In patients with COPD, long-acting bronchodilators are added if short-acting drugs are not controlling symptoms. They reduce breathlessness, decrease the risk of exacerbations and improve quality of life. ${ }^{6}$ However in patients with asthma, longacting bronchodilators should not be used without inhaled corticosteroids. Using long-acting beta ${ }_{2}$ agonists (LABAs) alone in asthma may increase the risk of asthma-related death. Similar caution is recommended in asthma-COPD overlap. ${ }^{3}$

LABAs are added to inhaled corticosteroids in patients with asthma if symptoms remain uncontrolled. Tiotropium, a long-acting muscarinic antagonist (LAMA), can be considered as an add-on to inhaled corticosteroid/LABA maintenance therapy in patients with moderate to severe asthma. ${ }^{19}$ Several LABA/LAMA combination inhalers are available (indacaterol/glycopyrronium, olodaterol/tiotropium, vilanterol/umeclidium and formoterol/aclidinium) and can be useful in patients with COPD whose symptoms are not controlled with a single longacting bronchodilator. However, these combination inhalers should not be used without a regular inhaled corticosteroid in patients in asthma-COPD overlap. ${ }^{14}$

\section{Inhaled corticosteroids}

Inhaled corticosteroids are the cornerstone of therapy for asthma. They decrease the risk of exacerbations, improve asthma control and decrease the loss of lung function over time. As inhaled corticosteroid monotherapy is not recommended for COPD, it is unclear if it is effective in asthma-COPD overlap. ${ }^{3}$ Despite this, guidelines recommend that regular, longterm inhaled corticosteroids should be prescribed for patients with asthma-COPD overlap..$^{14}$ Inhaled corticosteroids increase the risk of pneumonia in patients with COPD, ${ }^{20}$ so the lowest effective dose should be prescribed. ${ }^{14}$ 
In patients with COPD alone, inhaled corticosteroid/ LABA combination inhalers may be considered when there is a history of repeated exacerbations and $\mathrm{FEV}_{1}$ is less than $50 \%$ predicted. ${ }^{6}$ As patients with asthmaCOPD overlap have a higher symptom burden and more frequent exacerbations than those with COPD alone, it is likely that they will require a long-acting bronchodilator in addition to inhaled corticosteroids to control symptoms.

Patients using inhaled corticosteroids should be advised to rinse their mouth and spit after each dose. If they are using a manually actuated pressurised metered-dose inhaler, they should also be using a valved spacer.

\section{Exacerbations}

Flares of dyspnoea, wheeze, cough and sputum suggest an exacerbation of obstructive lung disease, and should be managed with increased doses of a short-acting bronchodilator and systemic glucocorticoids. For instance, salbutamol 4-8 puffs (400-800 microgram) via a spacer every 3-4 hours, and prednisolone 30-50 mg daily for five days (as a morning dose after the initial dose) can be given. If there are two out of three of fever, increased sputum volume or purulence, five days of doxycycline or amoxicillin are indicated. ${ }^{6}$

\section{Written action plan}

Guidelines recommend a written action plan as a component of self-management in COPD and asthma. ${ }^{6,14}$ The plan should include the patient's usual treatment and instructions on how to respond to deterioration. In patients with asthma-COPD overlap, an asthma or COPD action plan template can be used, depending on the dominant clinical features. ${ }^{14}$ A library of Asthma Action Plan templates is available from the National Asthma Council Australia. A COPD Action Plan Kit is available from Lung Foundation Australia. Some GP practice software also links to Asthma Management Plans.

Pulmonary rehabilitation, including supervised exercise training and self-management education, reduces re-admission rates and improves quality of life in patients with COPD. Referral to a local program is recommended for patients with asthma-COPD overlap..$^{6,14}$

\section{Comorbidities}

COPD is chiefly a disease of older people so the prevalence of asthma-COPD overlap increases with age. Age-related physiological changes may contribute to airflow limitation. ${ }^{21}$ Comorbidities are frequent in older people and present challenges for management. GPs are well placed to identify comorbidities and their relative importance to the older person's quality of life, and to manage multidisciplinary care.

Cognitive impairment can affect self-management skills. Older people are less likely to use inhalers effectively. ${ }^{22}$ Dexterity may be affected by osteoarthritis and should be considered when choosing an inhaler device. A personalised selfmanagement program for older patients with asthma, which targeted barriers to self-care such as poor inhaler technique, limited understanding of the role of medicines, and environmental triggers, was shown to reduce exacerbations and improve quality of life. ${ }^{23}$ People with asthma-COPD overlap have often smoked and so are also at risk of cardiovascular disease. This is a common cause of death in patients with COPD. Symptoms such as dyspnoea and chest tightness can occur in both cardiovascular disease and asthma-COPD overlap. Osteoporosis frequently coexists due to limited physical activity, smoking and corticosteroid use. ${ }^{21}$

Polypharmacy is an important consequence of ageing and comorbidity. In people with overlapping asthma and COPD, there is an increased likelihood of drug-disease interactions, for example beta blockers used for ischaemic heart disease may lead to bronchospasm. When there are compelling cardiovascular indications for beta-blocker use, a cardioselective drug such as metoprolol can be trialled at the lowest effective dose.

\section{Future directions}

Asthma, COPD and asthma-COPD overlap are all heterogeneous disorders. The impact of various clinical features and biomarkers on the response to particular therapies requires clarification. Newer treatments for asthma, such as monoclonal antibodies targeting lgE or interleukin-5, may have a role in asthma-COPD overlap, and further studies are needed.

Macrolides have been studied for their antiinflammatory properties in asthma. ${ }^{24}$ Forty-eight weeks of azithromycin 500 mg three times per week was shown to reduce exacerbations and improve quality of life in a randomised controlled trial of adults with severe persistent symptomatic asthma. ${ }^{24}$ Long-term macrolide therapy has also been shown to decrease the rate of exacerbations in patients with COPD, but there are concerns about QTc prolongation and hearing loss. ${ }^{25}$ However, their role in asthmaCOPD overlap is yet to be determined, as are the implications for antimicrobial stewardship.

\section{Conclusion}

Evidence to guide the clinical management of asthma-COPD overlap is limited. Incorporating interventions that are useful in both COPD and asthma, as well as considering the dominant clinical features and comorbidities in an individual patient, can help tailor therapy. 
Bronchodilators are used for symptom control in patients with asthma-COPD overlap. Inhaled corticosteroids also have a vital role as these patients have features of asthma, whereas they are only recommended for some patients with COPD alone.
Patients with asthma-COPD overlap have a high symptom burden and frequent exacerbations. They will benefit from improving their self-management skills, including correct inhaler technique and the use of action plans. $<$

Conflict of interest: none declared

\section{REFERENCES}

1. Gibson PG, McDonald VM. Asthma-COPD overlap 2015: now we are six. Thorax 2015;70:683-91. https://doi.org/10.1136/ thoraxjnl-2014-206740

2. McDonald VM, Gibson PG. "To define is to limit": perspectives on asthma-COPD overlap syndrome and personalised medicine. Eur Respir J 2017;49:1700336. https://doi.org/10.1183/13993003.00336-2017

3. Maselli DJ, Hardin M, Christenson SA, Hanania NA, Hersh CP, Adams SG, et al. Clinical approach to the therapy of asthmaCOPD overlap. Chest 2019;155:168-77. https://doi.org/10.1016/ j.chest.2018.07.028

4. Global Initiative for Chronic Obstructive Lung Disease. Global strategy for the diagnosis, management, and prevention of chronic obstructive pulmonary disease (2020 report). http://www.goldcopd.org/gold-reports [cited 2019 Dec 24]

5. Jenkins C, FitzGerald JM, Martinez FJ, Postma DS, Rennard S, van der Molen T, et al. Diagnosis and management of asthma, COPD and asthma-COPD overlap among primary care physicians and respiratory/allergy specialists: A global survey. Clin Respir J 2019;13:355-67. https://doi.org/10.1111/cri.13016

6. Yang IA, Brown JL, George J, Jenkins S, McDonald CF, McDonald VM, et al. COPD-X Australian and New Zealand guidelines for the diagnosis and management of chronic obstructive pulmonary disease: 2017 update. Med J Aust 2017;207:436-42. https://doi.org/10.5694/mja17.00686

7. Postma DS, Rabe KF. The asthma-COPD overlap syndrome N Engl J Med 2015;373:1241-9. https://doi.org/10.1056/ NEJMra1411863

8. Singh D, Agusti A, Anzueto A, Barnes PJ, Bourbeau J, Celli BR, et al. Global strategy for the diagnosis, management, and prevention of chronic obstructive lung disease: the GOLD science committee report 2019. Eur Respir J 2019;53:1900164. https://doi.org/10.1183/13993003.00164-2019

9. Hardin M, Cho M, McDonald ML, Beaty T, Ramsdell J, Bhatt S, et al. The clinical and genetic features of COPD-asthma overlap syndrome. Eur Respir J 2014;44:341-50. https://doi.org/10.1183/09031936.00216013

10. Diaz-Guzman E, Khosravi M, Mannino DM. Asthma, chronic obstructive pulmonary disease, and mortality in the U.S. population. COPD 2011:8:400-7. https://doi.org/10.3109/ 15412555.2011 .611200

11. Vonk JM, Jongepier H, Panhuysen $\mathrm{Cl}$, Schouten JP, Bleecker ER, Postma DS. Risk factors associated with the presence of irreversible airflow limitation and reduced transfer coefficient in patients with asthma after 26 years of follow up. Thorax 2003;58:322-7. https://doi.org/10.1136/ thorax.58.4.322

12. Israel E, Reddel HK. Severe and difficult-to-treat asthma in adults. N Engl J Med 2017;377:965-76. https://doi.org/10.1056/ NEJMra1608969

13. Australian Technical Advisory Group on Immunisation (ATAGI). Australian immunisation handbook. Canberra: Australian Government Department of Health; 2018. https://immunisationhandbook.health.gov.au [cited 2019 Dec 24]
14. National Asthma Council Australia. Australian asthma handbook, version 2.0. Melbourne: National Asthma Council Australia; 2019. www.asthmahandbook.org.au [cited 2019 Dec 24]

15. Robson C, Baskar SR, Booy R, Ferguson PE, Gilroy N, Kok J, et al. Influenza: overview on prevention and therapy. Aust Prescr 2019:42:51-5. https://doi.org/10.18773/ austprescr.2019.013

16. Walters JA, Tang JN, Poole P, Wood-Baker R. Pneumococcal vaccines for preventing pneumonia in chronic obstructive pulmonary disease. Cochrane Database Syst Rev 2017:1:CD001390. https://doi.org/10.1002/14651858. CD001390.pub4

17. Chrystyn H, van der Palen J, Sharma R, Barnes N, Delafont B, Mahajan A, et al. Device errors in asthma and COPD: systematic literature review and meta-analysis. NPJ Prim Care Respir Med 2017;27:22. https://doi.org/ 10.1038/s41533-017-0016-z

18. Kocks JW, Chrystyn H, van der Palen J, Thomas M, Yates L, Landis $\mathrm{SH}$, et al. Systematic review of association between critical errors in inhalation and health outcomes in asthma and COPD. NPJ Prim Care Respir Med 2018:28:43. https://doi.org/10.1038/s41533-018-0110-x

19. Reddel HK, FitzGerald JM, Bateman ED, Bacharier LB, Becker A, Brusselle G, et al. GINA 2019: a fundamental change in asthma management: treatment of asthma with shortacting bronchodilators alone is no longer recommended for adults and adolescents. Eur Respir J 2019;53:1901046. https://doi.org/10.1183/13993003.01046-2019

20. Kew KM, Seniukovich A. Inhaled steroids and risk of pneumonia for chronic obstructive pulmonary disease. Cochrane Database Syst Rev 2014;CD010115. https://doi.org/ 10.1002/14651858.CD010115.pub2

21. McDonald VM, Higgins I, Gibson PG. Managing older patients with coexistent asthma and chronic obstructive pulmonary disease: diagnostic and therapeutic challenges. Drugs Aging 2013;30:1-17. https://doi.org/10.1007/s40266-012-0042-z

22. Quinet $P$, Young CA, Héritier F. The use of dry powder inhaler devices by elderly patients suffering from chronic obstructive pulmonary disease. Ann Phys Rehabil Med 2010;53:69-76. https://doi.org/10.1016/j.rehab.2009.11.001

23. Federman AD, O'Conor R, Mindlis I, Hoy-Rosas J, Hauser D, Lurio J, et al. Effect of a self-management support intervention on asthma outcomes in older adults: the SAMBA study randomized clinical trial. JAMA Intern Med 2019;179:1113-21. https://doi.org/10.1001/jamainternmed.2019.1201

24. Gibson PG, Yang IA, Upham JW, Reynolds PN, Hodge S, James AL, et al. Effect of azithromycin on asthma exacerbations and quality of life in adults with persisten uncontrolled asthma (AMAZES): a randomised, doubleblind, placebo-controlled trial. Lancet 2017;390:659-68. https://doi.org/10.1016/S0140-6736(17)31281-3

25. Cui Y, Luo L, Li C, Chen P, Chen Y. Long-term macrolide treatment for the prevention of acute exacerbations in COPD: a systematic review and meta-analysis. Int J Chron Obstruct Pulmon Dis 2018;13:3813-29. https://doi.org/10.2147/COPD.S181246

\section{FURTHER READING}

Jenkins C. Drugs for chronic obstructive pulmonary disease. Aust Prescr 2017;40:15-9. https://doi.org/10.18773/ austprescr.2017.003
Reddel HK, Lembke K, Zwar NJ. The cost of asthma medicines. Aust Prescr 2018;41:34-6. https://doi.org/10.18773/ austprescr.2018.011 